\title{
THE DYNAMICS OF URBANIZATIONS AND CONCOMITANT LAND USE LAND COVER TRANSFORMATIONS IN PLANNED AND QUASI-PLANNED URBAN SETTLEMENTS OF PAKISTAN
}

\author{
Zaman M. Haq ${ }^{1}$, Saqib Z. ${ }^{1}$, Atif S. Bokhari ${ }^{12^{*}}$, Akhtar N. ${ }^{1}$, Amir S. ${ }^{1}$ \\ ${ }^{1}$ GIS and Eco-Informatics Laboratory, Department of Environmental Science, International Islamic University, H-10, \\ Islamabad, 44000, Pakistan \\ ²Department of Geography, Government College, Asghar Mall, Rawalpindi, 46000, Pakistan \\ *Corresponding author: syedatifbokhari@gmail.com \\ Received: April 01 ${ }^{\text {th }}, 2020$ / Accepted: August 9 ${ }^{\text {th }}, 2020$ / Published: October $1^{\text {st }}, 2020$ \\ https://DOl-10.24057/2071-9388-2020-64
}

\begin{abstract}
An attempt has been made to compare the salient characteristics of LULC transformations in planned (Faisalabad) and quasi-planned (Jhang) urban settlements of Pakistan. The Landsat-5 TM, Landsat 7 EMT+ and Landsat-8 images of 1989 , 1999, 2009 and 2019, respectively, were retrieved and processed through google earth engine. The dynamics of LULC critically analyzed for the three periods 1989-1999, 1999-2009 and 2009-2019. The LULC analyzed in terms of quantity of change, gains, losses, and persistence of the study area examined carefully. The study mainly focuses on the LULC transformations of the previous 30 years (1989-2019). These 30 years witnessed massive physical expansions and LULC convergences. During this time interval, the built-up areas in these cities expanded, and productive agricultural land substantially squeezed. The spatialtemporal analysis of LULC changes calls for improvised strategies for the resilience of land and environmental resources. The direct beneficiaries of this research are resource managers and regional planners as well as others scientific community.
\end{abstract}

KEY WORDS: Landsat images, LULC mapping, LULC dynamics, Planned Settlement, Quasi-planned settlement, Pakistan

CITATION: Zaman M. Haq, Saqib Z., Atif S. Bokhari, Akhtar N., Amir S. (2020). The Dynamics Of Urbanizations And Concomitant Land Use Land CoverTransformations In Planned And Quasi-Planned Urban Settlements Of Pakistan. Geography, Environment, Sustainability, Vol.13, No 4, p. 107-120 https://DOI-10.24057/2071-9388-2020-64

Conflict of interests: The authors reported no potential conflict of interest.

\section{INTRODUCTION}

Land resources are indispensable for the existence of life in all forms (Pimentel and Pimentel, 2003). Human beings are a product of the land environment and it is this very environment that provides man the wherewithal for survival (Davis et al. 2009; Goudie 2018). The intrusions in the lithospheric environment by them are, primarily, conceived for acquiring food and sustaining socioeconomic progressions. The perception, action, and exchanges between human and land resources have witnessed many transformations. The phenomenon of permanent settlements stimulated man's role in changing the face of the earth (Metzger et al. 2006; Roberts 2013). The ensuing demographic transitions, also, have their peculiar imprints on the interrelationship between human and land resources. The advent of agriculture, the expansions in the permanent settlements, and socio-technological changes further redefine the orientation and magnitude of these exchanges (Larondelle et al. 2016; Seto et al. 2011). The resultant urbanization and associated lifestyle changes are now challenging the carrying capacity of the environment (Saarela and Rinne 2016; Elmqvist et al. 2013; Appiah et al. 2017; Cobbinah et al. 2015b; Cobbinah et al. 2015a).
The consequential implications produce different types of strains for city-based urbanization and in-situ urbanization. The city-based urbanization is a product of planned LULC modifications in natural landscapes, while, the in-situ urbanization are the gradual transformations of rural settlements into urban areas. It was during such conversions that the semi-planned or quasi-planned urban settlements evolved (Zhu et al. 2007; Iftikhar et al. 2018; Zhu 2002). The concomitant initiatives for developments in such quasi-planned (semi-planned) contextual settings blur the distinction between the urban and rural settlements (Zhu 2004; SUN et al. 2010).

Therefore, the planned and unplanned modifications in the urban land resources necessitate careful assessments. The Land Use Land Cover (LULC) assessments are a realistic option to quantify such transformations as are required for the resilience of land resources. The LULC is a combination of two distinctive terminologies, often used interchangeably, while, Land Cover (LC) describes the physical characteristics of land surface, Land Use (LU) focuses on the particular use of a certain land area. Hence, the term LU evaluates the functional utility of land from the perspective of its practical utility (Rawat and Kumar 2015). 
Presently, the LULC changes are intensifying (Tian et al. 2014) to an extent that they are now compromising the resilience of the hydrosphere, the lithosphere, and the atmosphere at all possible spatial scales (Adhikari and Hartemink 2016). The resultant alterations, thus, characteristically impact the terrestrial and aquatic ecosystems (Du and Huang 2017; De Groot et al. 2002; Lambin et al. 2000; Briassoulis 2000; Cai et al. 2016; Aguilar et al. 2003; Hamad et al. 2017; Rimal et al. 2018). Therefore, scholars such as Gill et al. (2008), Du and Huang (2017) and Rimal et al. (2018) emphasize scrupulous assessments of land resources as a mean to ameliorate the stresses. Consequently, LULC change-detection is gaining focus in research. These inclinations are obligatory to enhance the productivity of land resources (El-Kawy et al. 2011; Shalaby and Tateishi 2007).

Schneider et al. (2015), Appiah et al. (2017) and Rimal et al. (2018) delved on the causes responsible for the reported urbanization in the developing countries. They assiduously tried to decipher the ensuing impacts in the form of LULC changes on the urban landscape. The findings infer that these resource-stricken regions are rapidly transforming under the influence of globalization. The lack of awareness, capacity building, inconsistencies in the land-use policies, and paucity of resources are exacerbating the urban environmental degradation in these regions (Atif et al. 2018a; Bokhari et al. 2018; Amir et al. 2020). Resultantly, the urban environmental dilapidation is more pronounced in these countries as compared to the developed ones (Ahern et al. 2014; Cohen 2006). Environmental degradation has corollary impacts on social dilapidations in these regions. The emerging scenario is, thus, posing challenges for life and livelihood in developing countries like Pakistan (Amir et al. 2020).

The phenomena of permanent settlement started thousands of years ago in the Indus valley located in Pakistan (Kenoyer 1998; Kenoyer et al. 2013; Danino 2008).
The Indus valley civilization evolved in a depositional plain formed by the river Indus and its tributaries. The physiographic region is sub-divided into Upper and Lower Indus plains. The Upper Indus plain is the northern section formed by the Indus and its five eastern tributaries. The Lower Indus plain is the southern section and is solely developed by the Indus itself. The land area between the two adjoining streams in the Upper Indus plain is called a doab (river-interfluves). The upper Indus plain is subdivided in Sind Saghar; Chaj; Rechna and Bari doabs (Grewal 2004).These land areas offer fertile tract for abode and agriculture. Overtimes, a varied set of factors such as the canalization of Indus plains (Khan 1990) the migration (Valentine et al. 2015); the green revolution of 1960s in Pakistan (Ali et al. 2017; Byerlee and Siddiq 1994) and associated industrial and infrastructural developments stimulated population growth and urbanization in this geographical region (Farah et al. 2016). However, the expansion was not supported by the desired management initiatives and, thus, added to the misery of fragile urban ecological resources in these areas (Mayo, 2012).

Therefore, the LULC based impact assessments are incumbent for postulating preventive and curative measures to ensure socio-ecological and environmental resilience (El-Kawy et al. 2011; Shalaby and Tateishi 2007). It entails for reliable estimations and assessments based upon empirical findings. The advancements in the Remote Sensing (RS) and Geographic Information System (GIS) enable the measurements of all spatial-temporal LULC changes (La Rosa and Wiesmann 2013; Thapa 2012; Khalil 2017). Therefore, the reliance on RS and GIS is gaining recognition to ensure accurate estimation of land resource management (Naqvi et al. 2014; Rawat and Kumar 2015; Hegazy and Kaloop 2015).

The present study tries to compare the salient characteristics of LULC transformations in planned and quasi-planned urban settlements of Pakistan. The specific objectives of this study are 1) to compare the impacts of

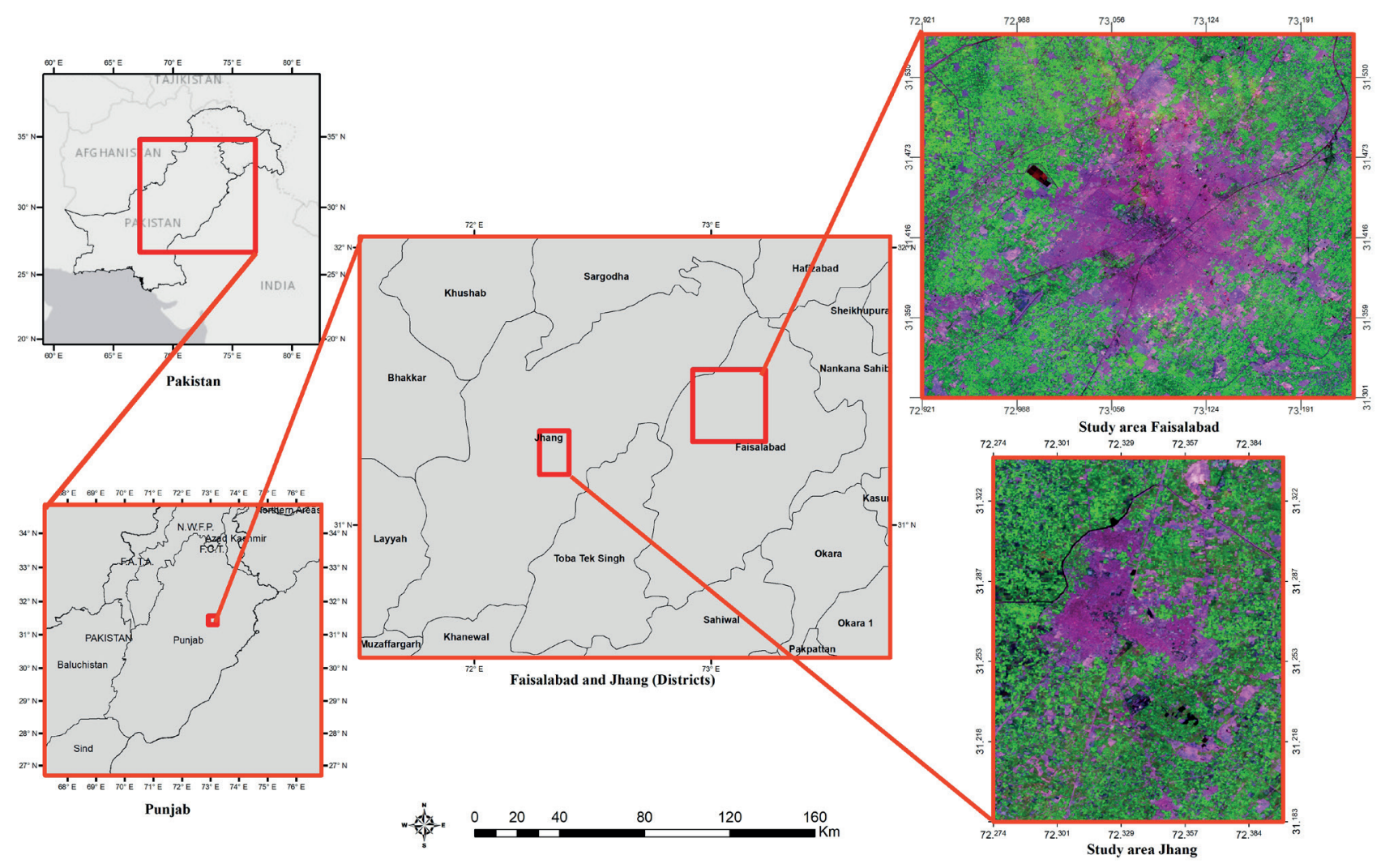

Fig. 1. Location map of study area 
urbanization on the LULC changes in urban Faisalabad and Jhang from 1989 to 2019, and 2) to quantify the changes in the selected LULC categories of these urban centers for a similar time period (1989-2019).

\section{MATERIALS AND METHODS}

The study area

The current investigation evaluates the impacts of urbanization on LULC changes in the urban areas of Pakistan. The study was carried out in the contrasting contextual settings of the Faisalabad and Jhang cities (Fig. 1). Whereas, these urban settlements are located in a similar physical environment i.e. Rechna doab (river-interfluve) of the Indus plain but evolved differently to cater for different socio-economic needs.

Faisalabad city is ranked third amongst the big cities of Pakistan, after Karachi and Lahore (https:// worldpopulationreview.com/world-cities/faisalabadpopulation). Faisalabad was conceived as a planned urban settlement. It was designed to serve as a trading centre for promoting agricultural activities during the colonial period (Stock and Chusid 2019). The subsequent industrialization and the accompanying demographic changes have their peculiar imprints on the LULC of this sprawling urban settlement. The urban area of Faisalabad stretches across an area of approximately $1163.60 \mathrm{~km}^{2}$. It lies between $72^{\circ}$ 55'15.041 E to $73^{\circ} 13^{\prime} 38.803$ eastern longitudes and from $31^{\circ} 33^{\prime} 44.988 \mathrm{~N}$ to $31^{\circ} 18^{\prime} 9.275$ northern latitudes.
Jhang is among the oldest districts of Punjab province (Steedman, 1882). While the Jhang city is a quasi-planned and agro-based urban settlement. It covers an area of approximately $287.64 \mathrm{~km}^{2}$. The urban center is located between $72^{\circ} 16^{\prime} 24.521 \mathrm{E}$ to $72^{\circ} 23^{\prime} 55.075 \mathrm{E}$ and from $31^{\circ} 20^{\prime} 27.309 \mathrm{~N}$ to $31^{\circ} 11^{\prime} 0.647 \mathrm{~N}$. The Jhang city is also expanding (https://worldpopulationreview.com/worldcities/jhang-population) but the speed and scale of urban sprawl in this city is slower than Faisalabad. Thus, the contextual settings of these cities enable us to comprehend the dynamics of LULC changes in the urban landscape of Pakistan.

\section{Data acquisition and assessment approach}

The spatial-temporal changes in the LULC of these cities were assessed through remotely sensed data. The selected satellite images span the complete study areas, i.e., Faisalabad (Path 150/Row 38) and Jhang (Path 150/Row 39) cities. The images were retrieved through Landsat-5 TM, Landsat 7 EMT+ and Landsat-8 (Annexure. 1). The required images at 30-meter resolution for the selected time intervals (1989-2019) are available in the archives of USGS/EROS (U.S. Geological Survey/Earth Resources Observation and Science) (https://www.usgs.gov). The images were processed online in the Google Earth Engine (GEE) platform (https://earthengine.google.com).

Image normalization is carried out prior to change detection. The criterion at work here is the Landsat Ecosystem Disturbance Adaptive Processing System (LEDAPS). Therefore, Top Of Atmosphere (TOA) reflectance

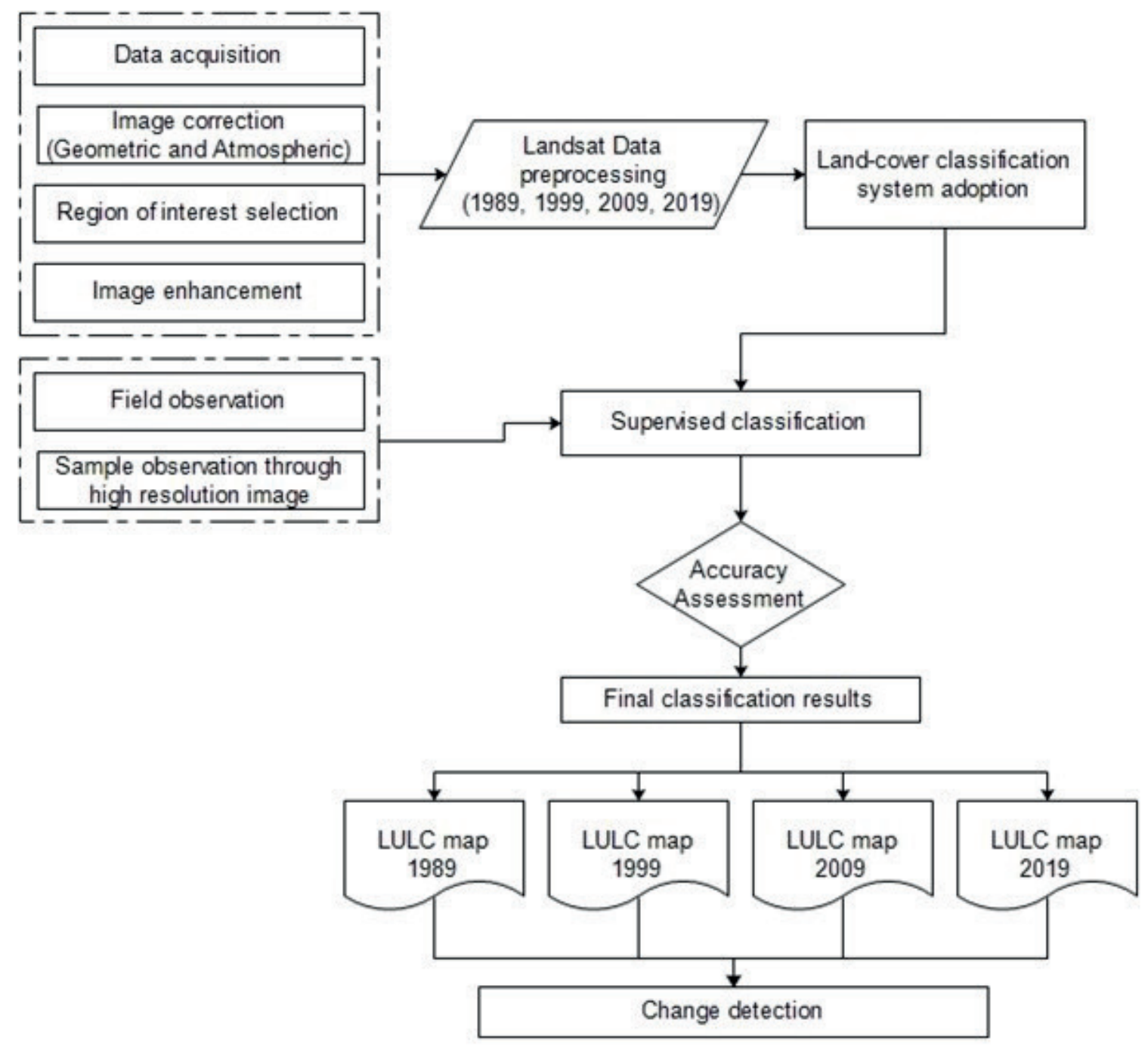

Fig. 2. The methodological framework for LULC change assessments 
Table 1. LULC Classes considered for Classification

\begin{tabular}{|c|c|}
\hline Class & Discerption \\
\hline Agriculture & $\begin{array}{r}\text { Planned crop land, Agriculture fallow land, herbaceous vegetation and crop, lands that are regularly used for hay and } \\
\text { grazing }\end{array}$ \\
\hline Barren & Areas of sparse vegetation cover that is likely to change or be converted to other uses in near future \\
\hline Built-up & $\begin{array}{r}\text { Areas covered by residential, commercial services, industrial, transportation, communications, industrial and commercial, } \\
\text { mixed urban or buildup land, airports, parking lots, highways, housing societies. }\end{array}$ \\
\hline Grasses & Characterized by high percentage of grasses, other herbaceous vegetation, city parks \\
\hline Trees & Areas covered by dense trees with relatively darker green colors, inner recreational areas, river line plantation \\
\hline Water & All areas of open water, generally with greater than 95\% cover of water, including lakes, streams, and reservoirs. \\
\hline
\end{tabular}

itemized by the bands 1 to 5 and 7 were adjudged relevant. The reference dataset and selected land cover classes were corroborated. The merger enables a quantification of the spatial-temporal changes in the designated LULC categories. Subsequently, the data was ported in the GIS environment to analyze, assess and illustrate oscillations in the observed land cover classes. Figure 2 succinctly illustrates the measures and mechanism deployed for the assessments.

\section{Land-Use/Land-Cover classification}

The research was confined to six classifiable LULC surfaces in the study area (Table 1). The field observations from 600 locations were carried out for quantitative assessments. These sites were marked with the help of the Global Positioning System (GPS). Besides, 2095 sample plots were manually observed from 1989 to 2019 through higher resolution images. For this purpose, the training and validation samples of each year were separately uploaded and integrated with the Google Fusion Tables (GFT) via GEE. For this purpose the Supervised and Un-supervised Classification techniques are considered standards (Shetty 2019; Prasad et al. 2006; Lewis 2000), and were, therefore, used (Table 1). For the land cover maps, the Classification and Regression Tree (CART) classifier was used because it is based upon the supervised classification mechanism.

\section{Accuracy assessment}

The accuracy assessment is a key feature and is useful to authenticate findings (Ahmadizadeh, 2014). The LULC based maps were cross-validated and scrutinized on the criteria of the Kappa test (Annexure 2).

\section{RESULTS}

\section{Spatial-temporal transformations in LULC}

The spatial-temporal assessments of LULC changes divulge the trajectories of urban expansions regarding these settlements. Therefore, the absolute and proportionate changes in the selected LULC classes during (1989-2019) in Faisalabad (Annexure 3) and Jhang cities (Annexure 4) were analysed. The illustrations (Fig. 3 and Fig. 4) succinctly portray the orientation and magnitude of such transformations in these settlements. The findings formulate that the agricultural land cover is shrinking, and built-up areas are expanding in both cities. The comparisons are portrayed with the help of a uniform intensity line. The line succinctly portrays the differences in the rate of LULC conversions between/among different contextual settings (Mondal et al. 2015). The line of uniform intensity (Fig. 5) inferred that the speed and magnitude of such conversions is more pronounced in Faisalabad as compared to Jhang.

Besides this, the urban sprawl in these settlements was observed more inclined towards the lines of communications such as highways and motorways (Fig. 3 and Fig. 4). Resultantly, the arable land cover is transforming into a non-productive and a barren one (Fig. 8 and Fig. 9). However, the phenomena of urban densification is gaining momentum in recent times. Consequently, the resultant vertical growth is gaining impetus in these cities.

\section{Quantitative assessments of LULC transformations}

The oscillations in each specific land use category for Faisalabad (Fig. 6) and Jhang cities (Fig. 7) were computed. Subsequently, the relative changes and consistencies in the proportion of these land use categories were assessed. The assessments formulate a noticeable increase in the proportion of tree cover, grassy surfaces, barren lands, and water surfaces of these settlements during (1989-2019). However, the significant fluctuations in the shares of water surfaces and barren lands are also observed (Fig. 3 and Fig. 4).

\section{Gross Gains, Losses and Persistence in LULC}

The impacts of urbanization during (1989-2019) on the persistence, increases, or decreases in the share of a specific land category were quantified. The findings have been summarized (Fig. 8 and Fig. 9) to depict the orientation and magnitude of such transformations (Fig. 6) and (Fig. 7). The findings revealed that such transformations were more pronounced from 1999 to 2009 (Fig. 8 and Fig. 9). However, the speed and scale of such changes was stunted in the following decade (2009 to 2019).

The assessments formulate that the agricultural land considerably reduced (-17.38\%) during (1989-2019) in Faisalabad (Fig. 8). Whereas, the percentage shares of all the other LULC categories remained stable or marginally enhanced during this time-frame. However, the most significant growth (16.05\%) was observed in the built-up areas of Faisalabad.

The proportionate shares of agricultural land significantly reduced in $(-8.93 \%)$ in Jhang city during (1989-2019). While, the proportions of tree covers (1.27\%), water surfaces (0.09\%), and grassy surfaces (0.03\%) marginally enhanced. However, the chunks of barren land (3.10\%) and built-up areas (4.44\%) substantially inflated in this city during this time interval (Fig. 9). 

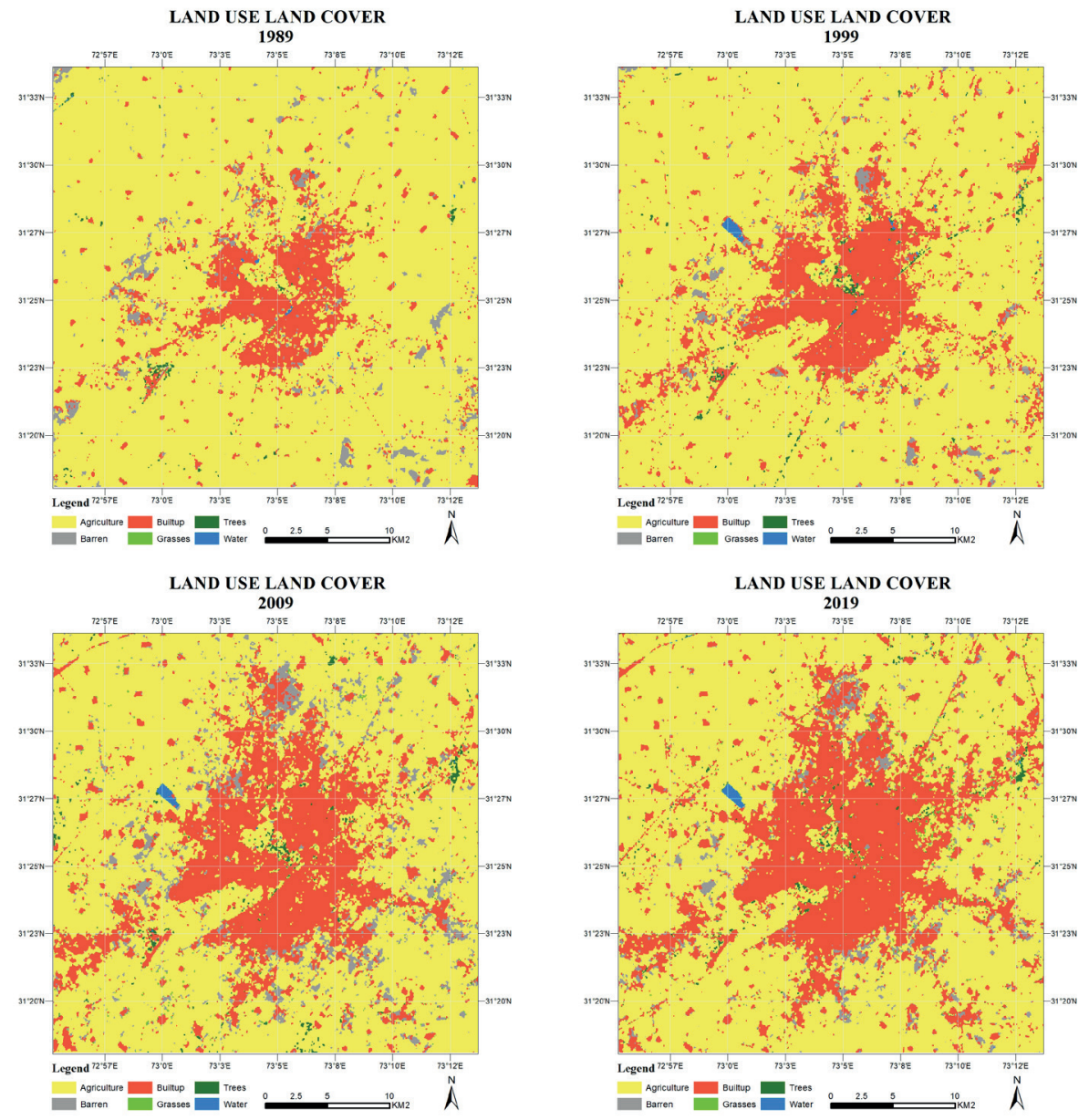

Fig. 3. Land use land cover classification maps of Faisalabad city
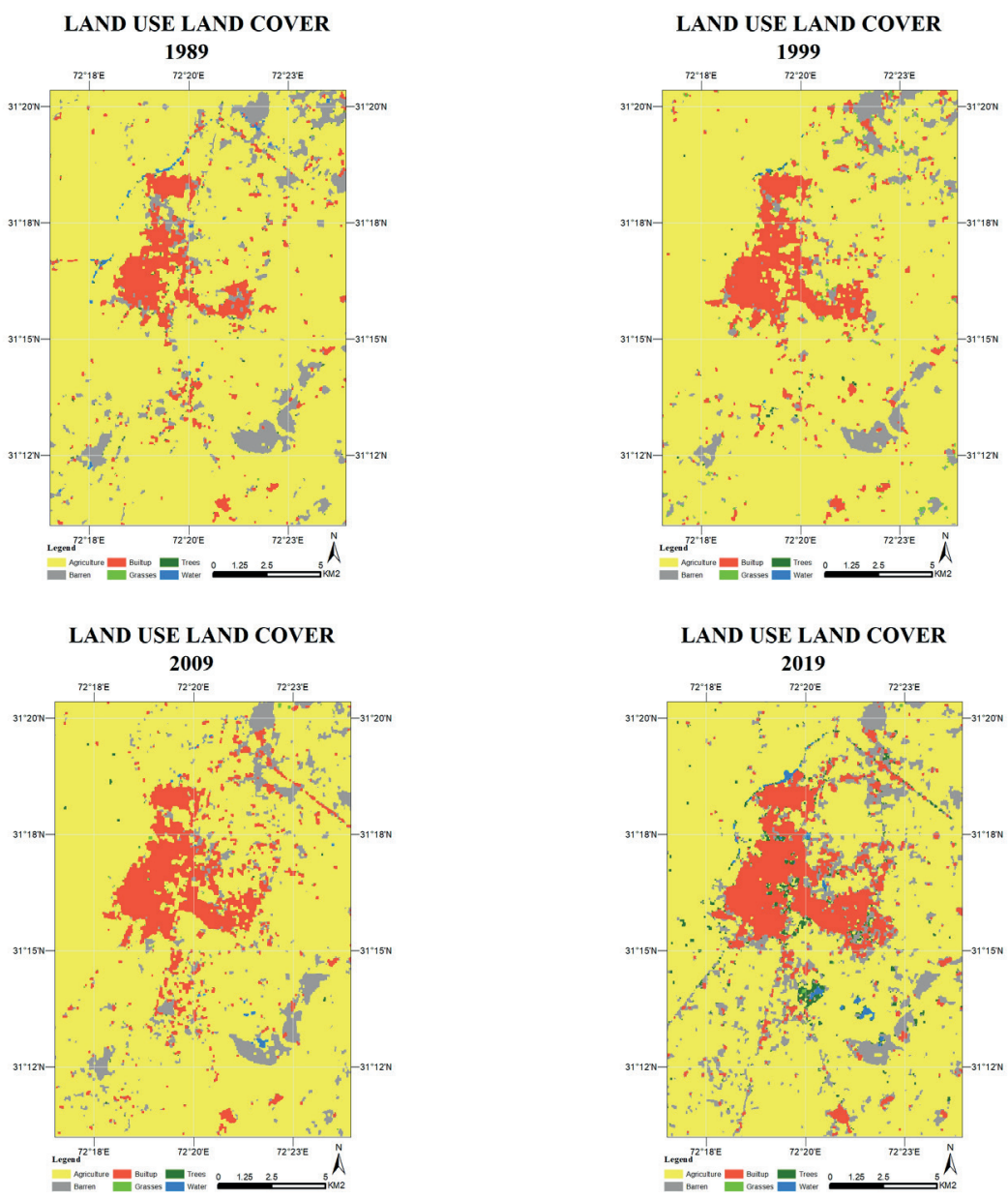

Fig. 4. Land use land cover classification maps of Jhang city Uniform Intensity Line 


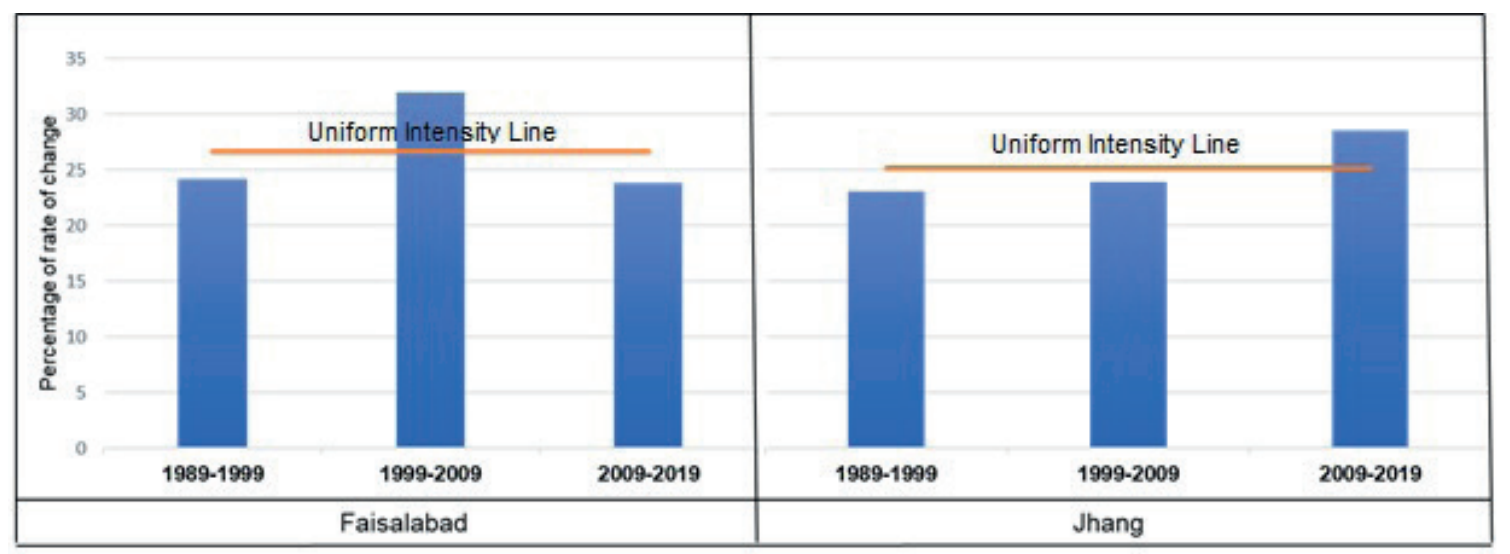

Fig. 5. The comparison of land conversion speed during the selected time intervals between Faisalabad and Jhang

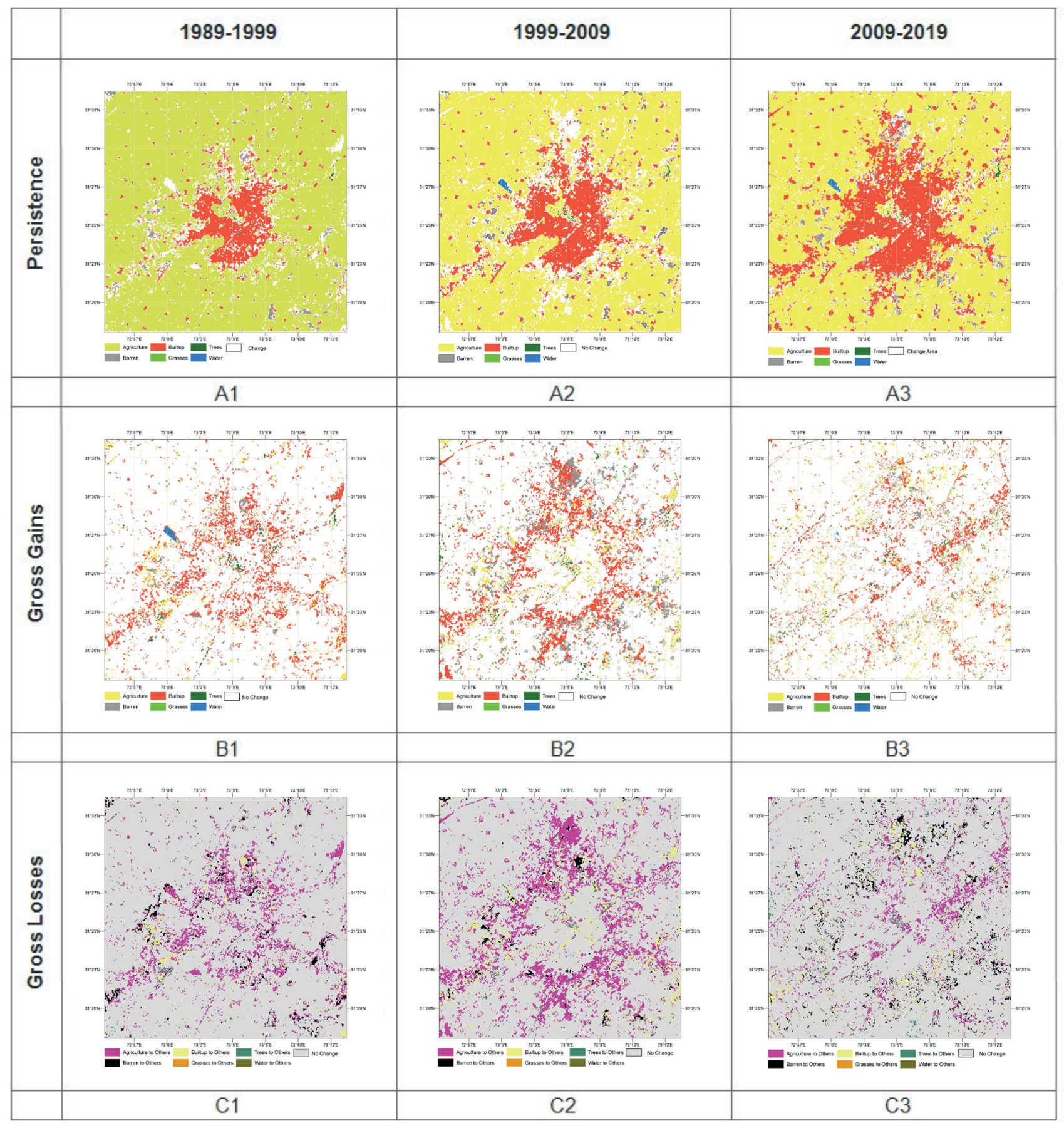

Fig. 6. Maps of persistence, gross gains and gross losses of urban center of Faisalabad 


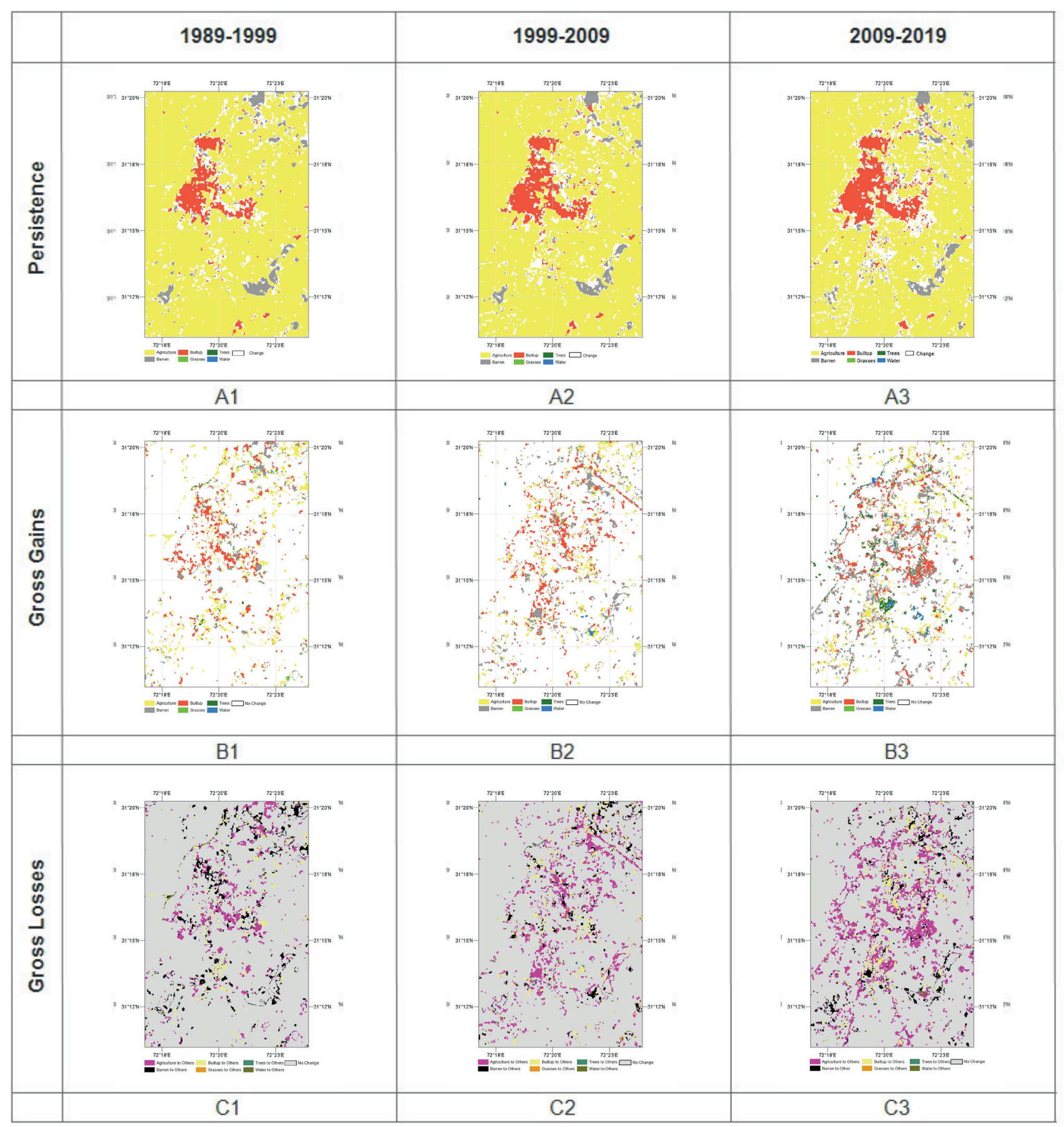

Fig. 7. Maps of persistence, gross gains and gross losses of urban center of Jhang 


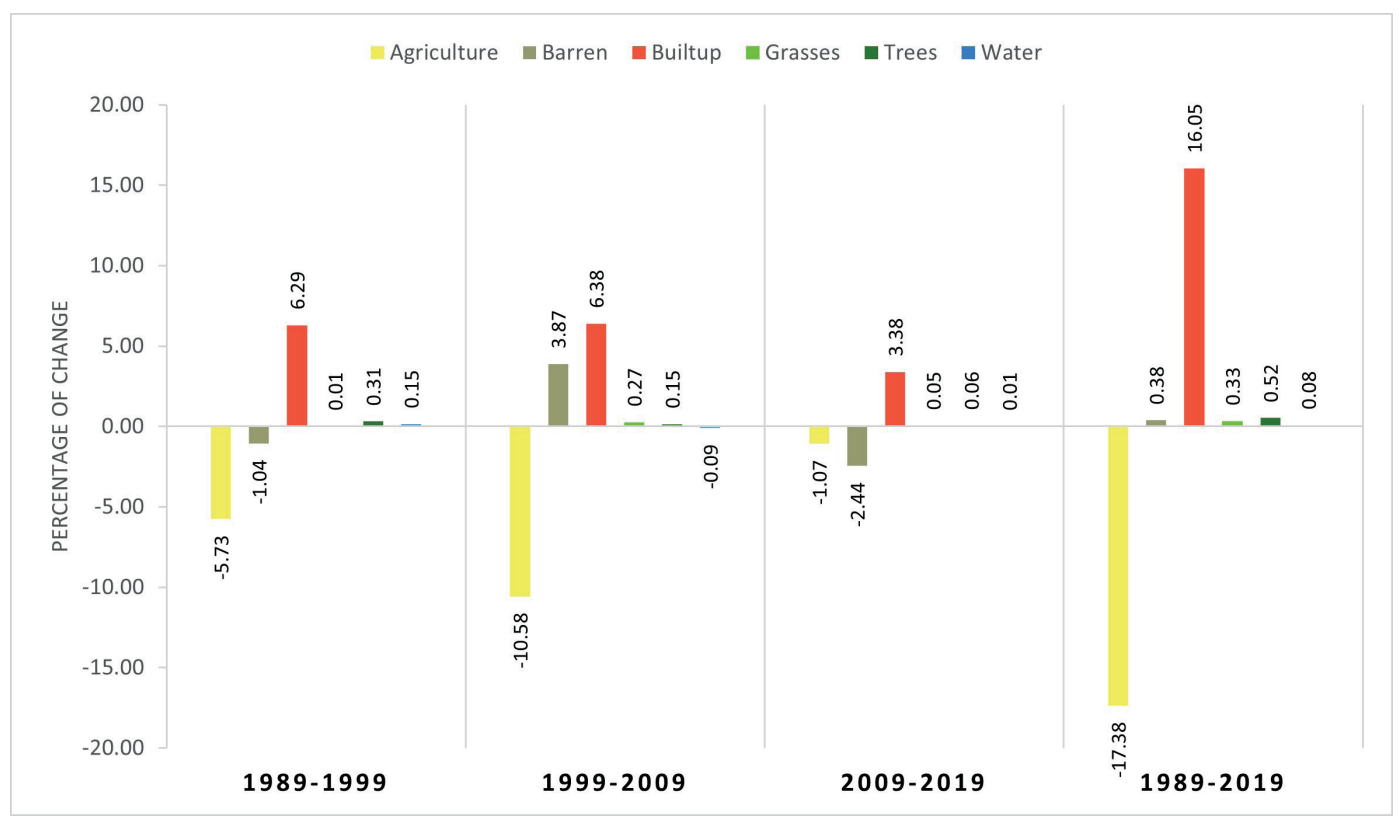

Fig. 8. Gains and losses in the LULC classes of Faisalabad (1989-2019)

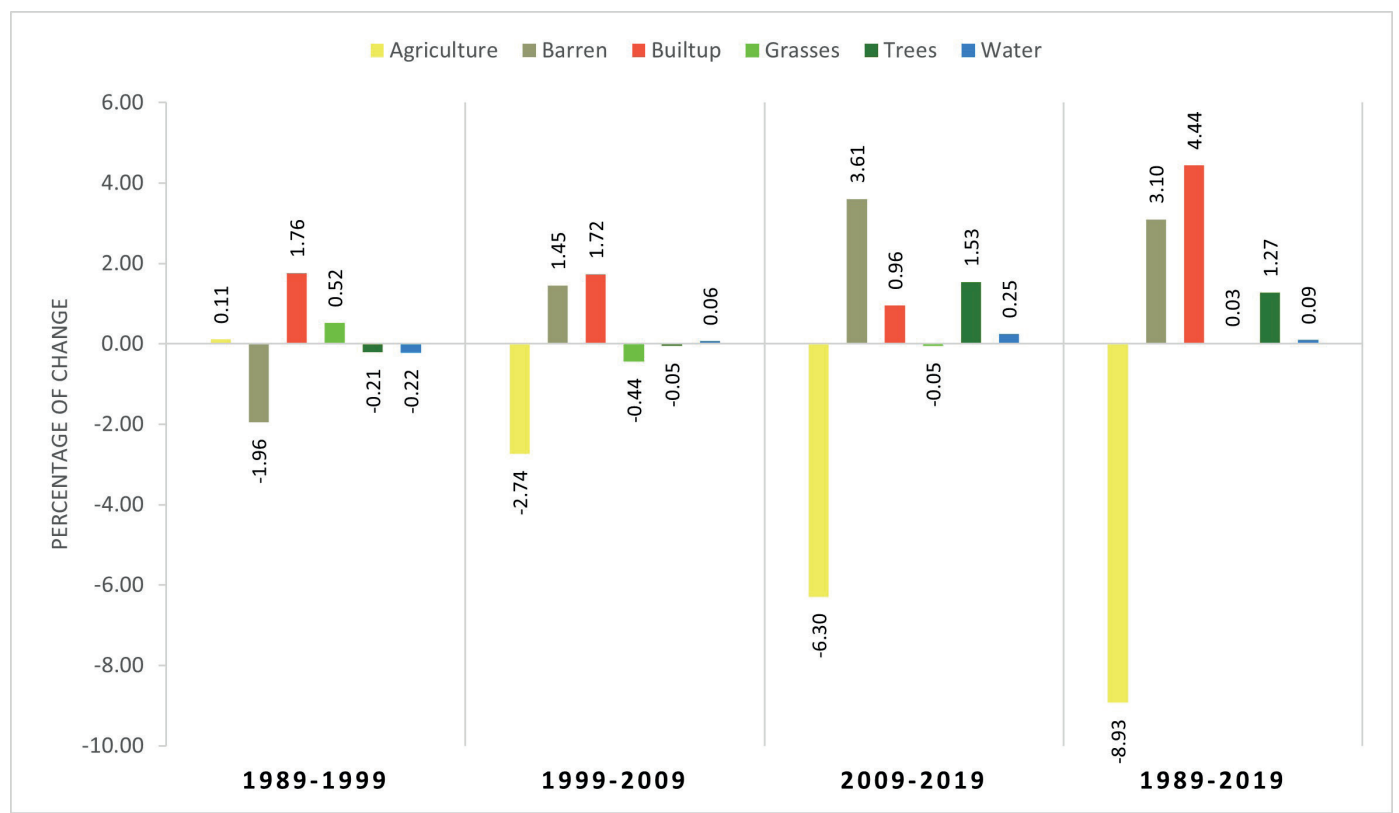

Fig. 9. Gains and losses in the lulc classes of Jhang (1989-2019)

\section{DISCUSSION}

Pakistan, like many other South Asian countries, has rapidly urbanized (Vasenev et al. 2019; Ouyang et al. 2016). The phenomenal increase in the rate and scale of urbanization in Pakistan (UNDP 2018; Shah et al. 2020) is attributed to the natural population growth (Kugelma, 2014) and rural-to-urban migration (Arif and Hami, 2009). This massive migration is attributable to the peculiar historic (Farooq et al. 2005; Farah et al. 2012; Safder and Babar 2019), social (Lopes and Farooq, 2020), economic (Chiesura and De Groot 2003; de Molina and Toledo 2014; Gilani et al. 2020), environmental (Shaheen et al. 2020) and geo-strategic (Shaheen et al. 2020) dynamics of this region.

The ensuing speed and impacts of urbanization in Pakistan (Nisar et al., 2013) are straining the urban land resources (Atif et al. 2018b; Atif et al. 2018a). It entails comprehending the dynamic and consequential impacts of the resultant changes in urban landscapes (Shao et al. 2005). The evolving scenario demands pragmatic responses based on empirical findings. Therefore, the research should be oriented more towards LULC assessments for the sustainability of urban land resources (Naqvi et al. 2014; Rawat and Kumar 2015; Hegazy and Kaloop 2015). The spatial-temporal analysis of LULC changes calls for improvised strategies for the resilience of land and environmental resources (Atif et al. 2018b).

The current study evaluates the spatial-temporal dimensions of the LULC changes regarding Faisalabad and Jhang cities (Annexure 3 and Annexure 4). The study mainly focuses on the LULC transformations of the previous 30 years (1989-2019). These 30 years witnessed massive physical expansions and LULC convergences (Fig. 3 and Fig. 4). During this time interval, the builtup areas in these cities expanded, and productive agricultural land substantially squeezed (Fig. 8 and Fig. 9). These observations substantiate the reported assertions that the accompanying processes of urbanization characteristically modify the LULC patterns (Butt et al. 2015; Ali et al. 2011; Ali and Malik 2010; Hassan et al. 2016). The findings of the study substantiate the notions that 
the reported population growth in these cities (Mazhar and Jamal 2011; Bukhari 1971; Farah et al. 2012; Ghalib et al. 2017) is stressing these urban centers

The chronological assessment of spatial expansions regarding Faisalabad formulates that the settlement was initially and intrinsically planned to serve as a market town. The area around Ghanta Ghar was designed to cater to the needs of the Central Business District (CBD). The initial extensions in the structure of Faisalabad city followed the pattern of the Concentric Zone Model (CZM). E. W. Burgess proposed it in 1923 (Brown and Holmes 1971). The model hypothesized that urban settlements expand outward from a central location like the water ripples in a pond. This urban settlement expanded outward from the CBD like the growth rings of a tree. The urban neighborhoods such as Jinnah Colony, Tata Bazaar, and Civil Lines developed during the early phases of urban expansion. The process of urban sprawl was expedited with the advent of canalization, and the subsequent industrial and manufacturing activities. However, the lateral growths in the city followed the orientation of road infrastructure. The demographic pressures, lacunas in the policies, and compromises over urban land management deter any possibility of a planned urban growth (Omwoma 2016). Besides this, the loose regulatory control encouraged unplanned and irregular LULC transformations in Faisalabad (Saeed et al. 2012; Shakeel et al. 2015). Resultantly, the unplanned and congested residential localities like Duglus Pura; Sant Nagar; Dhobi Ghaat; Islam Nagar emerged. These observations corroborate the notions that integrated management of urban environmental resources is a prerequisite for the socio-ecological resilience of urban life (Atif et al. 2018a).

While the historic city of Jhang is an autogenously developed human settlement it evolved without any formal planning. The embedded flaws of the earlier developments, still, haunt the process of urbanization in the Jhang city. The imprints of irregular growth are visible in such localities as Kot Akbar, Ludhan Shah, Loharan wali, Jalal Abad and Deewan wali. The provisioning of civic facilities is cumbersome in these unplanned, congested and irregular neighborhoods. The findings entail that a coordinated urban planning is obligatory for environmentally friendly urban growth. Therefore, the recent trends of urban expansion in Jhang city were adjudged more skewed towards organized and planned growth. These tendencies are quite visible in the form and structure of the recently developed Satellite town, Lal Zar Housing Schemes (Phase-1 and 2), Ali Garden and Al-Karam City etc. The planned orientations in these expansions are due to public pressures (Haaland and van Den Bosch 2015). These findings construe that consciousness about environmental issues is positively contributing to urban planning in Pakistan. Contrarily, the demographic and economic stresses are culpable for unintended urban sprawl.

The impacts of road infrastructure on the process of urbanization were also evaluated. The recent urban expansions were observed more tilted towards intercity highways and motorways during (1989-2019). These observations corroborate the postulations of sector theory. The model was envisaged by Homer Hoyt (Beauregard 2007; Ju et al. 2016). It formulates that urban expansions intensify along the lines of communications i.e., roads and railway networks.

The findings of this study substantiate that the RS and GIS-based understandings facilitate in deciphering the spatial-temporal connotations of urbanization (La Rosa and Wiesmann 2013). The findings corroborate the reported notions such as (La Rosa and Wiesmann 2013; Thapa 2012; Khalil 2017) regarding the robustness of RS and GIS techniques. These resources were also found appropriate for detecting previous changes in the LULC (El-Kawy et al. 2011). Therefore, the reliance on such costeffective resources is a pragmatic option for developing economies such as Pakistan.

\section{CONCLUSIONS}

The holistic assessments of this study imply that the people in developing countries move towards urban areas for economic opportunities. The resultant uncontrolled urbanization and concomitant LULC transformations are adversely impacting the urban infrastructures. Therefore, integrated measures are obligatory to regulate the speed and scale of such LULC conversions. Besides this, the inflow of people is promoting horizontal and vertical growth in the city structure. The resultant impacts stress the ecological and environmental resources of the cities and their peripheral zones. The emerging scenario is proving burdensome specifically for the resource stricken regions. The massive urban growth, due to migration is exacerbating the urban social life of these countries. The scenario entails for synchronization in policies and an integration of efforts for a more resilient urban development. The decentralization of power is a pragmatic option for countries such as Pakistan. It will productively contribute towards curtailing the inflow of migrants from rural hinterlands towards the more central places like Faisalabad and Jhang. The creation of employment opportunities in the rural hinterlands is another viable preference to ameliorate stresses on urban infrastructures. However, the findings affirm that population control is the most reliable measure to address such daunting challenges in countries like Pakistan (Heinke 1997; Simon 2019).

\section{REFERENCES}

Adhikari K. and Hartemink A.E. (2016). Linking soils to ecosystem services-A global review. Geoderma, 262, 101-111.

Aguilar A.G., Ward P.M. and Smith Sr C. (2003). Globalization, regional development, and mega-city expansion in Latin America: analyzing Mexico City's peri-urban hinterland. Cities, 20(1), 3-21.

Aher, J., Cilliers S. and Niemelä J. (2014). The concept of ecosystem services in adaptive urban planning and design: A framework for supporting innovation. Landscape and Urban Planning, 125, 254-259.

Ahmadizadeh S. (2014). Land use change detection using remote sensing and artificial neural network: Application to Birjand, Iran. Computational Ecology and Software, 4(4), 276

Ali G., Ashraf A., Bashir M.K. and Cui S. (2017). Exploring environmental Kuznets curve (EKC) in relation to green revolution: a case study of Pakistan. Environmental Science \& Policy, 77, 166-171.

Ali M., Khan S.J., Aslam I. and Khan Z. (2011). Simulation of the impacts of land-use change on surface runoff of Lai Nullah Basin in Islamabad, Pakistan. Landscape and Urban Planning, 102(4), 271-279. 
Ali S.M. and Malik R.N. (2010). Vegetation communities of urban open spaces: Green belts and parks in Islamabad city. Pak. J. Bot, 42(2), 1031-1039.

Amir S., Saqib Z., Khan M.I., Khan M.A., Bokhari S.A., Zaman-UI-Haq M. and Majid A. (2020). Farmers' perceptions and adaptation practices to climate change in rain-fed area: a case study from district Chakwal, Pakistan. Pakistan Journal of Agricultural Sciences, 57(2), 465-475.

Appiah, D. O., Forkuo E. K., Bugri J.T. and Apreku T. O. (2017). Geospatial Analysis of Land Use and Land Cover Transitions from 1986-2014 in a Peri-Urban Ghana. Geosciences, 7(4), 125.

Arif G. and Hamid S. (2009). Urbanization, city growth and quality of life in Pakistan. European Journal of Social Sciences, 10(2), $196-215$. Atif S., Saqib Z., Ali A. and Zaman M. (2018a). The impacts of socio-economic factors on the perception of residents about urban vegetation: a comparative study of planned versus semi-planned cities of Islamabad and Rawalpindi, Pakistan. Applied Ecology and Environmental Research, 16(4), 4265-4287.

Atif S., Saqib Z., Ali A., Zaman M., Akhtar N., Fatima H., Atif M. and Farooqi S. (2018b). Identification of key-trends and evaluation of contemporary research regarding urban ecosystem services: a path towards socio-ecological sustainability of urban areas. Applied Ecology and Environmental Research, 16(3), 3545-3581. 248-271

Beauregard R. (2007). More Than Sector Theory: Homer Hoyt's Contributions to Planning Knowledge. Journal of Planning History, 6(3),

Bokhari S., Saqib Z., Ali A. and Zaman-Ul-Haq M. (2018). Perception of Residents about Urban Vegetation: A Comparative Study of Planned Versus Semi-Planned Cities of Islamabad and Rawal pindi, Pakistan. Journal of Ecosystem \& Ecography, 8(251), 2.

Briassoulis H. (2000). Analysis of land use change: theoretical and modeling approaches. Regional Research Institute, West Virginia University Morgantown, WV.

Brown L.A. and Holmes J. (1971). Intra-urban migrant lifelines: a spatial view. Demography, 8(1), 103-122.

Bukhari M. (1971). Growth and development of Lyallpurcity. Pakistan Geographical Review, 26(2), 1-15.

Butt A., Shabbir R., Ahmad S. S. and Aziz N. (2015). Land use change mapping and analysis using Remote Sensing and GIS: A case study of Simly watershed, Islamabad, Pakistan. The Egyptian Journal of Remote Sensing and Space Science, 18(2), 251-259.

Byerlee D. and Siddiq A. (1994). Has the green revolution been sustained? The quantitative impact of the seed-fertilizer revolution in Pakistan revisited. World Development, 22(9), 1345-1361.

Cai Y.-B., Li H.-M., Ye X.-Y. and Zhang H. (2016). Analyzing three-decadal patterns of land use/land cover change and regional ecosystem services at the landscape level: Case study of two coastal metropolitan regions, eastern china. Sustainability, 8(8), 773.

Chiesura A. and De Groot R. (2003). Critical natural capital: a socio-cultural perspective. Ecological Economics, 44(2), $219-231$.

Cobbinah P.B., Erdiaw-Kwasie M.O. and Amoateng P. (2015a). Africa's urbanisation: Implications for sustainable development. Cities, 47, 62-72.

Cobbinah P.B., Erdiaw-Kwasie M.O. and Amoateng P. (2015b). Rethinking sustainable development within the framework of poverty and urbanisation in developing countries. Environmental Development, 13, 18-32.

Cohen B. (2006). Urbanization in developing countries: Current trends, future projections, and key challenges for sustainability. Technology in society, 28(1-2), 63-80.

Danino M. (2008). New insights into Harappan town-planning, proportions, and units, with special reference to Dholavia. Man and Environment, 33(1), 66-79.

Davis J.L., Green J.D. and Reed A. (2009). Interdependence with the environment: Commitment, interconnectedness, and environmental behavior. Journal of environmental psychology, 29(2), 173-180.

De Groot R.S., Wilson M.A. and Boumans R.M. (2002). A typology for the classification, description and valuation of ecosystem functions, goods and services. Ecological economics, 41(3), 393-408.

De Molina M.G. and Toledo V.M. (2014). Social Metabolism at the Local Scale. The Social Metabolism. Springer.

Du X. and Huang Z. (2017). Ecological and environmental effects of land use change in rapid urbanization: The case of hangzhou, China. Ecological Indicators, 81243-251.

El-Kawy O.A., Rød J., Ismail H. and Suliman A. (2011). Land use and land cover change detection in the western Nile delta of Egypt using remote sensing data. Applied Geography, 31(2), 483-494.

Elmqvist T., Fragkias M., Goodness J., Güneralp B., Marcotullio P.J., Mcdonald R.I., Parnell S., Schewenius M., Sendstad M. and Seto K.C. (2013). Urbanization, biodiversity and ecosystem services: challenges and opportunities: a global assessment, Springer.

Farah N., Khan I.A., Manzoor A. and Shahbaz B. (2016). Changing Land Ownership Patterns and Agricultural Activities in the Context of Urban Expansion in Faisalabad, Pakistan. Pakistan Journal of Life \& Social Sciences, 14(3).

Farah N., Zafar M.I. and Nawaz N. (2012). Socio-Economic and Cultural Factors Affecting Migration Behavior in District Faisalabad, Pakistan. Pakistan Journal of Life \& Social Sciences, 10(1), 28-32.

Farooq M., Mateen A. and Cheema M. (2005). Determinants of migration in Punjab, Pakistan: A case study of Faisalabad metropolitan. Journal of Agriculture and Social Sciences (Pakistan).

Ghalib A., Qadir A. and Ahmad S. (2017). Evaluation of developmental progress in some cities of punjab, pakistan, using urban sustainability indicators. Sustainability, 9(8), 1473.

Gilani H., Ahmad S., Qazi W.A., Abubakar S.M. and Khalid M. (2020). Monitoring of Urban Landscape Ecology Dynamics of Islamabad Capital Territory (ICT), Pakistan, Over Four Decades (1976-2016). Land, 9(4), 123.

Gill S.E., Handley J.F., Ennos A.R., Pauleit S., Theuray N. and Lindley S.J. (2008). Characterising the urban environment of UK cities and towns: A template for landscape planning. Landscape and urban planning, 87(3), 210-222.

Goudie A.S. (2018). Human impact on the natural environment, John Wiley \& Sons.

Grewal J. (2004). Historical geography of the Punjab. JPS, 11(1), 2.

Haaland C. and Van Den Bosch C.K. (2015). Challenges and strategies for urban green-space planning in cities undergoing densification: A review. Urban forestry \& urban greening, 14(4), 760-771.

Hamad R., Balzter H. and Kolo K. (2017). Multi-criteria assessment of land cover dynamic changes in halgurd sakran national park (HSNP), kurdistan region of Iraq, using remote sensing and GIS. Land, 6(1), 18.

Hassan Z., Shabbir R., Ahmad S.S., Malik A. H., Aziz N., Butt A. and Erum S. (2016). Dynamics of land use and land cover change (LULCC) using geospatial techniques: a case study of Islamabad Pakistan. SpringerPlus, 5(1), 1-11. 
Hegazy I.R. and Kaloop M.R. (2015). Monitoring urban growth and land use change detection with GIS and remote sensing techniques in Daqahlia governorate Egypt. International Journal of Sustainable Built Environment, 4(1), 117-124.

Heinke G.W. (1997). The challenge of urban growth and sustainable development for Asian cities in the 21st century. Environmental monitoring and assessment, 44(1-3), 155-171.

United Nations population estimates and projections of major Urban Agglomerations [Online]. Available: https://worldpopulationreview. com/world-cities/faisalabad-population [Accessed 30-07-2020]

United Nations population estimates and projections of major Urban Agglomerations [Online]. Available: https://worldpopulationreview. com/world-cities/jhang-population [Accessed 30-07-2020].

Iftikhar M.N., Ali S. and Sarzynski A. (2018). Community-government partnership for metered clean drinking water: A case study of Bhalwal, Pakistan. Climate Change in Cities. Springer.

J, C., Zhou X. and He Q. (2016). On the application of a concentric zone model (CZM) for classifying and extracting urban boundaries using night-time stable light data in Urumqi of Xinjiang, China. Remote sensing letters, 7(11), 1033-1042.

Kenoye J.M. (1998). Ancient cities of the Indus valley civilization, Oxford University Press Karachi.

Kenoye J.M., Price T.D. and Burton J.H. (2013). A new approach to tracking connections between the Indus Valley and Mesopotamia: initial results of strontium isotope analyses from Harappa and Ur. Journal of Archaeological Science, 40(5), 2286-2297.

Khali R. Z. (2017). InSAR coherence-based land cover classification of Okara, Pakistan. The Egyptian Journal of Remote Sensing and Space Science.

Kha M.S. (1990). The impact of human activities on the status and distribution of amphibians in Pakistan. Hamadryad, 15(1), 21-24.

Kugelma, M. (2014). Pakistan's Runaway Urbanization: What Can Be Done? Asia Program, Woodrow Wilson International Center for Scholars.

La Rosa D. and Wiesmann D. (2013). Land cover and impervious surface extraction using parametric and non-parametric algorithms from the open-source software R: An application to sustainable urban planning in Sicily. GlScience \& remote sensing, 50(2), 231-250.

Lambin E.F., Rounsevell M. and Geist H. (2000). Are agricultural land-use models able to predict changes in land-use intensity? Agriculture, Ecosystems \& Environment, 82(1-3), 321-331.

Larondelle, N., Frantzeskaki N. and Haase D. (2016). Mapping transition potential with stakeholder-and policy-driven scenarios in Rotterdam City. Ecological Indicators, 70, 630-643.

Lewis R.J. (2000). An introduction to classification and regression tree (CART) analysis. Annual meeting of the society for academic emergency medicine in San Francisco, California.

Lopes N.V.M. and Farooq S. (2020). Smart City Governance Model for Pakistan. Smart Governance for Cities: Perspectives and Experiences. Springer.

Mayo S.M. (2012). Determination of urban settlement pattern for optimal regional development in Punjab. University of Engineering and Technology Lahore-Pakistan.

Mazhar F. and Jamal T. (2011). Temporal population growth of Faisalabad city. Pakistan Journal of Science, 63(4), $249-251$.

Metzger M., Rounsevell M., Acosta-Michlik L., Leemans R. and Schröter D. (2006). The vulnerability of ecosystem services to land use change. Agriculture, ecosystems \& environment, 114(1), 69-85

Mondal M., Sharma N., Kappas M. and Garg P. (2015). Critical assessment of land use land cover dynamics using multi-temporal satellite images. Environments, 2(1), 61-90.

Naqvi H. R., Siddiqui L., Devi L. M. and Siddiqui M. A. (2014). Landscape transformation analysis employing compound interest formula in the Nun Nadi Watershed, India. The Egyptian Journal of Remote Sensing and Space Science, 17(2), 149-157.

Nisar A., Akram A. and Hussain H. (2013). Determinants of internal migration in Pakistan. The Journal of Commerce, 5(3), 32.

Omwoma R.M. (2016). A Land-tenure Based Model for Guiding and Controlling Development on Freehold Land in Urban Areas: Exploring Possibilities for Management of Spatial Quality in Kenya.

Ouyang Z., Fan P. and Chen J. (2016). Urban built-up areas in transitional economies of Southeast Asia: Spatial extent and dynamics. Remote Sensing, 8(10), 819.

Pimentel D. and Pimentel M. (2003). World population, food, natural resources, and survival. World Futures: The Journal of General Evolution, 59(3-4), 145-167.

Prasad A.M., Iverson L.R. and Liaw A. (2006). Newer classification and regression tree techniques: bagging and random forests for ecological prediction. Ecosystems, 9(2), 181-199.

Rawat J. and Kumar M. (2015). Monitoring land use/cover change using remote sensing and GIS techniques: A case study of Hawalbagh block, district Almora, Uttarakhand, India. The Egyptian Journal of Remote Sensing and Space Science, 18(1), 77-84.

Rimal B., Zhang L., Stork N., Sloan S. and Rijal S. (2018). Urban Expansion Occurred at the Expense of Agricultural Lands in the Tarai Region of Nepal from 1989 to 2016. Sustainability (2071-1050), 10(5).

Roberts B. (2013). Landscapes of settlement: prehistory to the present, Routledge.

Saarela S.-R. and Rinne J. (2016). Knowledge brokering and boundary work for ecosystem service indicators. An urban case study in Finland. Ecological Indicators, 6149-62.

Saeed Q., Bhatti l., Ashraf A. and Ahmad B. (2012). Physiochemical Analysis of Drinking Water from Different Urban Areas of Faisalabad. International Journal of Basic \& Applied Sciences IJBAS-IJENS, 12(6), 183-186.

Safder Q. and Babar U. (2019). Assessment of Urbanization and Urban Sprawl Analysis through Remote Sensing and GIS: A Case Study of Faisalabad, Punjab Pakistan. INTERNATIONAL JOURNAL OF ACADEMIC RESEARCH IN BUSINESS AND SOCIAL SCIENCES, 9(4).

Schneider A., Mertes C., Tatem A., Tan B., Sulla-Menashe D., Graves S., Patel N., Horton J., Gaughan A. and Rollo J. (2015). A new urban landscape in East-Southeast Asia, 2000-2010. Environmental Research Letters, 10(3), 034002.

Seto K.C., Fragkias M., Güneralp B. and Reilly M. K. (2011). A meta-analysis of global urban land expansion. PloS one, 6(8), e23777.

Shah S.A.R., Naqvi S.A.A. and Anwar S. (2020). Exploring the linkage among energy intensity, carbon emission and urbanization in Pakistan: fresh evidence from ecological modernization and environment transition theories. Environmental Science and Pollution Research, $1-23$.

Shaheen A., Sheng J., Arshad S., Salam S. and Hafeez M. (2020). The Dynamic Linkage between Income, Energy Consumption, Urbanization and Carbon Emissions in Pakistan. Polish Journal of Environmental Studies, 29(1), 267-276. 
Shakeel M., Khan A.U., Munir A.R. and Ahmed T. (2015). Spatial Variation in Urban Air Pollution: A GIS Based Approach in Faisalabad, Pakistan. Asian Journal of Natural \& Applied Sciences, 4(3), 40-48.

Shalaby A. and Tateishi R. (2007). Remote sensing and GIS for mapping and monitoring land cover and land-use changes in the Northwestern coastal zone of Egypt. Applied Geography, 27(1), 28-41.

Shetty S. (2019). Analysis of Machine Learning Classifiers for LULC Classification on Google Earth Engine. University of Twente, Netherlands.

Simon J.L. (2019). The economics of population growth, Princeton University Press, New Jersey.

Steedman E.B. (1882). Report on the Revised Settlement of the Jhang District of the Punjab, 1874-1880, W. Ball.

Stock J.L. and Chusid J.M. (2019). Urbanizing India's frontier: Sriganganagar and canal-town planning on the Indus plains. Planning Perspectives, 1-24.

Sun Q., Xu J. and Chi X. (2010). A study of planning of commercial-net in quasi-urbanization area: taking luogang district in guangzhou as an example. Journal of South China Normal University (Natural Science Edition), (2), 27.

Thapa R.B. (2012). Monitoring landscape change in Kathmandu metropolitan region using multi-temporal satellite imagery. SPIE AsiaPacific Remote Sensing, 85281-85281.

Tian H., Banger K., Bo T. and Dadhwal V. K. (2014). History of land use in India during 1880-2010: Large-scale land transformations reconstructed from satellite data and historical archives. Global and Planetary Change, 12178-88.

Undp (2018). «Human Development Reports». The 2016 Global Multidimensional Poverty Index (MPI).

Valentine B., Kamenov G.D., Kenoyer J.M., Shinde V., Mushrif-Tripathy V., Otarola-Castillo E. and Krigbaum J. (2015). Evidence for patterns of selective urban migration in the Greater Indus Valley (2600-1900 BC): a lead and strontium isotope mortuary analysis. PLoS One, 10(4), e0123103.

Vasenev V.I., Yaroslavtsev A.M., Vasenev I.I., Demina S.A. and Dovltetyarova E.A. (2019). Land-use change in new Moscow: First outcomes after five years of urbanization. Geography, Environment, Sustainability, 12(4), 24-34.

Zhu Y. (2002). Beyond large-city-centred urbanisation: in situ transformationof rural areas in Fujian Province. Asia pacific viewpoint, 43(1), $9-22$.

Zhu Y. (2004). Changing urbanization processes and in situ rural-urban transformation: reflections on China's settlement definitions. New forms of urbanization: Beyond the urban-rural dichotomy. Ashgate Publishing Ltd.

Zhu Y., Qi X., Shao H. and He K. (2007). The evolution of in situ urbanization and quasi-urban populations and their planning and environmental implications in China: Case studies from Quanzhou Municipality. Centre for Population and Development Research, Fujian Normal University, China. 


\section{Appendix}

Appendix 1. Satellite images characteristics

\begin{tabular}{|c|c|c|c|c|c|c|c|c|c|}
\hline \multirow{2}{*}{ Path/Raw } & \multirow{2}{*}{ Year } & \multirow{2}{*}{ Satellite } & \multirow{2}{*}{ Sensor } & \multirow{2}{*}{$\begin{array}{c}\text { Data } \\
\text { Acquired }\end{array}$} & \multirow{2}{*}{$\begin{array}{l}\text { Thermal } \\
\text { Resolution }\end{array}$} & \multirow{2}{*}{$\begin{array}{l}\text { Radiometric } \\
\text { Resolution }\end{array}$} & \multicolumn{3}{|c|}{ Bands Description } \\
\hline & & & & & & & Name & Wavelength ( $\mu \mathrm{m})$ & Discerption \\
\hline \multirow{3}{*}{$149 / 38$} & \multirow{6}{*}{1989} & \multirow{6}{*}{ Landsat 5} & \multirow{6}{*}{ TM } & \multirow{3}{*}{$\begin{array}{c}1989-06- \\
19\end{array}$} & \multirow{6}{*}{16 Days } & \multirow{6}{*}{8 bit } & B1 & $0.45-0.52$ & Blue \\
\hline & & & & & & & B2 & $0.52-0.60$ & Green \\
\hline & & & & & & & B3 & $0.63-0.69$ & Red \\
\hline \multirow{3}{*}{$150 / 38$} & & & & & & & B4 & $0.77-0.90$ & Near infrared \\
\hline & & & & $\begin{array}{l}\text { 1989-04- } \\
11\end{array}$ & & & B5 & $1.55-1.75$ & Shortwave infrared 1 \\
\hline & & & & & & & B7 & $2.08-2.35$ & Shortwave infrared 2 \\
\hline & \multirow{6}{*}{1999} & \multirow{6}{*}{ Landsat 5} & \multirow{6}{*}{ TM } & \multirow{3}{*}{$\begin{array}{c}\text { 1999-05- } \\
14\end{array}$} & \multirow{6}{*}{16 Days } & \multirow{6}{*}{ 8bit } & B1 & $0.45-0.52$ & Blue \\
\hline $149 / 38$ & & & & & & & B2 & $0.52-0.60$ & Green \\
\hline & & & & & & & B3 & $0.63-0.69$ & Red \\
\hline \multirow{3}{*}{$150 / 38$} & & & & & & & B4 & $0.77-0.90$ & Near infrared \\
\hline & & & & $\begin{array}{c}1999-04- \\
24\end{array}$ & & & B5 & $1.55-1.75$ & Shortwave infrared 1 \\
\hline & & & & & & & B7 & $2.08-2.35$ & Shortwave infrared 2 \\
\hline & \multirow{6}{*}{2009} & \multirow{6}{*}{ Landsat 7} & \multirow{6}{*}{ ETM+ } & \multirow{3}{*}{$\begin{array}{c}2009-06- \\
16\end{array}$} & \multirow{6}{*}{16 Days } & \multirow{6}{*}{ 8bit } & B1 & $0.45-0.52$ & Blue \\
\hline $149 / 38$ & & & & & & & B2 & $0.52-0.60$ & Green \\
\hline & & & & & & & B3 & $0.63-0.69$ & Red \\
\hline \multirow{3}{*}{$150 / 38$} & & & & \multirow{3}{*}{$\begin{array}{c}2009-05- \\
23\end{array}$} & & & B4 & $0.77-0.90$ & Near infrared \\
\hline & & & & & & & B5 & $1.55-1.75$ & Shortwave infrared 1 \\
\hline & & & & & & & B7 & $2.08-2.35$ & Shortwave infrared 2 \\
\hline & & & & & & & B2 & $0.45-0.51$ & Blue \\
\hline & & & & 2019-06- & & & B3 & $0.53-0.59$ & Green \\
\hline $149 / 38$ & & & & 01 & & & B4 & $0.64-0.67$ & Red \\
\hline & 2019 & Landsat 8 & TOA & & 16 Days & 16bit & B5 & $0.85-0.88$ & Near infrared \\
\hline & & & & & & & B7 & $2.11-2.29$ & Shortwave infrared 2 \\
\hline $150 / 38$ & & & & $\begin{array}{l}\text { 2019-04- } \\
17\end{array}$ & & & B10 & $10.60-11.19$ & Thermal infrared 1 \\
\hline & & & & & & & B11 & $11.50-12.51$ & Thermal infrared 2 \\
\hline
\end{tabular}

Appendix 2. Accuracy assessment for each classified image

\begin{tabular}{|c|c|c|c|c|}
\hline \multirow{4}{*}{ Image (Path/Raw) } & Year & Classified Image & $\begin{array}{c}\text { Overall Classification } \\
\text { accuracy }\end{array}$ & Overall Kappa Statistics \\
\hline \multirow{3}{*}{ Urban Center of Faisalabad (149/38) } & 1989 & Landsat 5 TM & $81.73 \%$ & 0.6863 \\
\cline { 2 - 5 } & 1999 & Landsat 5 TM & $86.42 \%$ & 0.7478 \\
\cline { 2 - 5 } & 2009 & Landsat 7 EMT+ & $83.93 \%$ & 0.7068 \\
\cline { 2 - 5 } & 2019 & Landsat 8 TOA & $91.11 \%$ & 0.9285 \\
\hline \multirow{3}{*}{ Urban Center of Jhang (150/38) } & 1989 & Landsat 5 TM & $82.33 \%$ & 0.6923 \\
\cline { 2 - 5 } & 1999 & Landsat 5 TM & $87.23 \%$ & 0.7631 \\
\cline { 2 - 5 } & 2009 & Landsat 7 EMT+ & $81.53 \%$ & 0.7958 \\
\cline { 2 - 5 } & 2019 & Landsat 8 TOA & $89.41 \%$ & 0.9101 \\
\hline
\end{tabular}


Appendix 3. Land Use Land Cover (LULC) area of Urban Center of Faisalabad

\begin{tabular}{|c|c|c|c|c|c|c|c|c|c|}
\hline & & \multicolumn{2}{|c|}{1989} & \multicolumn{2}{|c|}{1999} & \multicolumn{2}{c|}{2009} & \multicolumn{2}{c|}{2019} \\
\hline Sr. No & Class & Area $\left(\mathrm{km}^{2}\right)$ & Area $(\%)$ & Area $\left(\mathrm{km}^{2}\right)$ & Area $(\%)$ & Area $\left(\mathrm{km}^{2}\right)$ & Area $(\%)$ & Area $\left(\mathrm{km}^{2}\right)$ & Area $(\%)$ \\
\hline 1 & Agriculture & 1003.57 & 86.25 & 936.87 & 80.51 & 813.78 & 69.94 & 801.38 & 68.87 \\
\hline 2 & Barren & 33.33 & 2.86 & 21.23 & 1.82 & 66.22 & 5.69 & 37.80 & 3.25 \\
\hline 3 & Buildup & 121.60 & 10.45 & 194.80 & 16.74 & 269.07 & 23.12 & 308.39 & 26.50 \\
\hline 4 & Grasses & 0.06 & 0.01 & 0.23 & 0.02 & 3.33 & 0.29 & 3.96 & 0.34 \\
\hline 5 & Trees & 4.16 & 0.36 & 7.80 & 0.67 & 9.54 & 0.82 & 10.25 & 0.88 \\
\hline 6 & Water & 0.87 & 0.07 & 2.66 & 0.23 & 1.65 & 0.14 & 1.82 & 0.16 \\
\hline \multicolumn{2}{|c|}{ Total } & 1163.60 & 100.00 & 1163.60 & 100.00 & 1163.60 & 100.00 & 1163.60 & 100.00 \\
\hline
\end{tabular}

Appendix 4. Land Use Land Cover (LULC) area of Urban Center of Jhang

\begin{tabular}{|c|c|c|c|c|c|c|c|c|c|}
\hline & & \multicolumn{2}{|c|}{1989} & \multicolumn{2}{|c|}{1999} & \multicolumn{2}{c|}{2009} & \multicolumn{2}{c|}{2019} \\
\hline Sr. No & Class & Area $\left(\mathrm{km}^{2}\right)$ & Area $(\%)$ & Area $\left(\mathrm{km}^{2}\right)$ & Area $(\%)$ & Area $\left(\mathrm{km}^{2}\right)$ & Area $(\%)$ & Area $\left(\mathrm{km}^{2}\right)$ & Area $(\%)$ \\
\hline 1 & Agriculture & 244.96 & 85.16 & 245.27 & 85.27 & 237.39 & 82.53 & 219.28 & 76.23 \\
\hline 2 & Barren & 21.35 & 7.42 & 15.73 & 5.47 & 19.89 & 6.91 & 30.26 & 10.52 \\
\hline 3 & Buildup & 19.44 & 6.76 & 24.49 & 8.52 & 29.45 & 10.24 & 32.20 & 11.20 \\
\hline 4 & Grasses & 0.05 & 0.02 & 1.54 & 0.54 & 0.27 & 0.09 & 0.14 & 0.05 \\
\hline 5 & Trees & 1.05 & 0.36 & 0.44 & 0.15 & 0.29 & 0.10 & 4.70 & 1.63 \\
\hline 6 & Water & 0.79 & 0.27 & 0.16 & 0.06 & 0.35 & 0.12 & 1.06 & 0.37 \\
\hline \multicolumn{2}{|c|}{ Total } & 287.64 & 100.00 & 287.64 & 100.00 & 287.64 & 100.00 & 287.64 & 100.00 \\
\hline
\end{tabular}

